\title{
HIV/AIDS Awareness among VCT Clients: A Cross-Sectional Study from Delhi, India
}

\author{
Bhanu Mehra, Sonali Bhattar, Preena Bhalla, and Deepti Rawat \\ Department of Microbiology, Maulana Azad Medical College, New Delhi 110002, India \\ Correspondence should be addressed to Preena Bhalla; preenabhalla@gmail.com
}

Received 27 February 2014; Accepted 9 May 2014; Published 4 June 2014

Academic Editor: Luenda Charles

Copyright ( 2014 Bhanu Mehra et al. This is an open access article distributed under the Creative Commons Attribution License, which permits unrestricted use, distribution, and reproduction in any medium, provided the original work is properly cited.

\begin{abstract}
The contribution of India to the global burden of HIV/AIDS is significant. A major barrier that the country has faced in its battle against this disease is the inadequate and inaccurate information about it among the population. The present analysis explores the knowledge about HIV/AIDS among clients attending a voluntary counselling and testing (VCT) facility in India. Two hundred clients attending the VCT facility were assessed in this regard using a structured predesigned questionnaire. Sixty-three (31.5\%) of the respondents had never heard of HIV/AIDS. In comparison to males, a significantly higher number of females had not heard about the disease $(P<0.01)$. Lower levels of education of participants were found to be significantly associated with the response of not having heard of HIV/AIDS $(P<0.01)$ as was an occupation status of being an unemployed man/housewife $(P=0.002)$. For the 137 (68.5\%) respondents who had heard about HIV/AIDS, television was the source of information in 130 (94.9\%) followed by posters in $93(67.9 \%)$ and newspapers in $88(64.2 \%)$. While the knowledge about HIV transmission and prevention was good, the extent of misconceptions was high (61.8\%). Our study highlights the strong need to raise the levels of HIV awareness among Indian population.
\end{abstract}

\section{Introduction}

Human immunodeficiency virus (HIV)/acquired immunodeficiency syndrome (AIDS) is a major and one of the most serious public health challenges in today's world. An estimated 35.3 million people across the world are infected with HIV [1]. According to the joint United Nations programme on HIV/AIDS (UNAIDS), HIV is one of the leading causes of mortality across the globe [2]. A major proportion of HIV infected individuals reside in the developing world, of which the populous countries of the Asian subcontinent are of major concern.

The contribution of India to the global burden of HIV/AIDS is significant with nearly 2.39 million people currently affected with the disease in the country [3]. Though the HIV prevalence in India is low, the large population base of the country explains this enormous absolute number of HIV infected. The large population base also makes the country more vulnerable to HIV. In addition several other factors contribute to this vulnerability including low levels of education, poverty, early age of sexual debut, limited access to health services especially in rural settings, inadequate information about modes of HIV transmission, and misconceptions and myths revolving around HIV/AIDS [4].

Among these a major barrier in the battle against HIV/AIDS has been inadequate and inaccurate information that further perpetuates various forms of social stigmas and discriminations against the HIV infected. The synonymous interpretation of HIV/AIDS to immorality would result in hesitation on part of the people to get themselves tested for HIV infection leaving a large number of HIV infected individuals unaware of their status. This could be potentially devastating as it would accelerate the unknowing, unchecked, and silent transmission of HIV infection from the infected to the naive population. Low levels of education would also leave the population unaware of the HIV risk reduction strategies. Another matter of concern is the changing face of HIV epidemic in India. The epidemic has crossed the conventional boundaries of the traditional high risk groups where it initially started and has now percolated into the general population [5]. Undoubtedly, India has emerged as the new epicentre of this international epidemic. 
A bipronged approach has been employed to limit the disastrous consequences of this epidemic. The first strategy is promoting HIV awareness and knowledge among the population through media as well as through voluntary counselling and testing (VCT) facilities so as to empower the individuals to protect themselves by adopting safe sexual practices and other necessary precautionary measures. The second approach is increased and easy accessibility to antiretroviral therapy to reduce the mortality due to HIV/AIDS. Though antiretroviral drugs can slow down the progression of this disease, they are not curative. Moreover, an effective HIV vaccine is also far from reality. Therefore the only feasible and cost-effective approach in the current situation, especially in the developing world, would be to disseminate among the general population correct, accurate, and complete knowledge about HIV/AIDS transmission modes, risk factors, preventive measures, and available therapeutic options. In this context, education has often been described as a "social vaccine" with information, education, and communication (IEC) being considered the key tools of HIV prevention.

A number of studies have attempted to explore the peoples' perceptions about HIV/AIDS. The present analysis was undertaken as an attempt to assess the extent of knowledge about HIV/AIDS among clients attending a VCT facility in India and to correlate their levels of awareness with various sociodemographic determinants.

\section{Materials and Methods}

The present cross-sectional analysis was conducted at the VCT facility of a tertiary care health centre situated in Delhi, India. The VCT caters to nearly 1100 clients per month. The study population is comprised of clients attending the VCT facility in November-December 2013. Two hundred consecutive clients who were 18 years of age and above and who verbally consented to participate in the interviews after the primary purpose of the study was explained to them were enrolled in the analysis. The interviews were conducted by the investigators before the clients underwent the HIV counselling sessions. All the interviews were voluntary and confidential.

A standardised, structured predesigned questionnaire was employed and was translated into Hindi, which is the commonly used and fully understood language of this region. The same procedure was followed by the interviewers for all the participants whether literate or nonliterate and the responses were recorded. The interviews were conducted independently by two senior resident doctors and the quality of the questionnaire and of the personal interviews was assessed by the faculty in charge of the VCT. The questionnaire is comprised of two broad sections. The first section dealt with the sociodemographic characteristics of the participants (age, sex, education, marital status, type of family, occupation, and place of residence). While "nuclear family" was defined as a household consisting of a father, a mother, and their children all in one household dwelling, the term "joint family" was used to describe a family composed of parents, their children, and the children's spouses and offspring all in one household. The names of the participants were not entered so as to maintain anonymity and confidentiality.

The second section of the questionnaire sought to explore the participants' awareness regarding various aspects of HIV/AIDS. This section comprised only close-ended questions, the answers to which were recorded as yes/no/I do not know. The participants were initially questioned if they had ever heard of HIV/AIDS. Only those respondents who claimed to have heard of HIV/AIDS were questioned further. These participants were asked about the source of their information about HIV/AIDS. Their level of awareness regarding modes of HIV transmission was judged by their ability to correctly identify the four principal ways by which this infection can spread. By incorporating misleading questions in the panel, we attempted to simultaneously explore and identify some common misconceptions that prevail among Indian population pertaining to modes of HIV transmission. In the subsequent questions the participants' perception regarding availability of possible treatment options and their knowledge about preventive measures/practices of HIV/AIDS were assessed.

For data analysis of responses to the questions concerning modes of transmission, treatment, and prevention of HIV/AIDS, participants with an "I do not know" response were also considered unaware about the concerned aspect as were the participants with a "No" response. For analyzing the responses to the panel of questions dealing with misconceptions, respondents with "No" response to all the questions were categorized as having "no misconception" while those with a "Yes" response to even one of the questions were categorized as having "at least one misconception."

Data entry was performed using Microsoft Excel sheet. All the entries were doubly checked for any possible keyboard errors. Data was analyzed using the Epi Info software, and Chi-square and Fischer's exact test were applied to determine the difference of proportion between qualitative variables. A $P$ value less than 0.05 was considered as statistically significant.

\section{Results}

Of the 200 study subjects included in this analysis, $46(23 \%)$ were $18-24$ years, 75 (37.5\%) were $25-31$ years, $43(21.5 \%)$ were $32-38$ years, $25(12.5 \%)$ were $39-45$ years, $3(1.5 \%)$ were 46-50 years, and $8(4 \%)$ were more than 50 years of age. The mean age of the study participants was $30.85 \pm 9.10$ years with a range of $18-62$ years. Eighty (40\%) of the 200 participants were males and $120(60 \%)$ were females. One hundred and sixty $(80 \%)$ of the respondents were married while 40 (20\%) were unmarried. Fifty-eight (29\%) of the participants were nonliterate, 68 (34\%) were educated up to primary school level, 50 (25\%) were educated up to secondary school level, and only 24 (12\%) had an education level of college and above. Majority of the respondents, that is, 117 $(58.5 \%)$, were unemployed men or housewives, $25(12.5 \%)$ were daily wagers, 39 (19.5\%) were salaried, and 19 (9.5\%) 
TABLE 1: Sociodemographic profile of study population.

\begin{tabular}{|c|c|c|}
\hline Sociodemographic variable & Number $(n=200)$ & Percentage (\%) \\
\hline \multicolumn{3}{|l|}{ Age group (years) } \\
\hline $18-24$ years & 46 & $23 \%$ \\
\hline $25-31$ years & 75 & $37.5 \%$ \\
\hline $32-38$ years & 43 & $21.5 \%$ \\
\hline $39-45$ years & 25 & $12.5 \%$ \\
\hline $46-50$ years & 3 & $1.5 \%$ \\
\hline$>50$ years & 8 & $4 \%$ \\
\hline \multicolumn{3}{|l|}{ Gender } \\
\hline Male & 80 & $40 \%$ \\
\hline Female & 120 & $60 \%$ \\
\hline \multicolumn{3}{|l|}{ Marital status } \\
\hline Single & 40 & $20 \%$ \\
\hline Married & 160 & $80 \%$ \\
\hline \multicolumn{3}{|l|}{ Education } \\
\hline Nonliterate & 58 & $29 \%$ \\
\hline Primary & 68 & $34 \%$ \\
\hline Secondary & 50 & $25 \%$ \\
\hline College and above & 24 & $12 \%$ \\
\hline \multicolumn{3}{|l|}{ Occupation } \\
\hline Unemployed/housewives & 117 & $58.5 \%$ \\
\hline Daily wages & 25 & $12.5 \%$ \\
\hline Salaried & 39 & $19.5 \%$ \\
\hline Business & 19 & $9.5 \%$ \\
\hline \multicolumn{3}{|l|}{ Type of residence } \\
\hline Rural & 88 & $44 \%$ \\
\hline Urban & 112 & $56 \%$ \\
\hline \multicolumn{3}{|l|}{ Type of family } \\
\hline Nuclear & 108 & $54 \%$ \\
\hline Joint & 92 & $46 \%$ \\
\hline
\end{tabular}

belonged to business class. Of the 200 respondents who participated, 88 (44\%) belonged to rural areas while 112 $(56 \%)$ resided in urban localities. Majority of the respondents (54\%) were from nuclear families and the remaining (46\%) belonged to joint families. The sociodemographic profile of the study population is summarised in Table 1.

Sixty-three (31.5\%) of the respondents admitted that they had never heard of HIV/AIDS. The percentage of females (42.5\%) who had never heard of HIV/AIDS was significantly higher than the corresponding percentage of males (15\%) $(P<0.01)$. A statistically significant association was also noted between the response "not heard about HIV/AIDS" and the education level of the participants $(P<0.01)$ and we observed that the percentage of respondents who had not heard about HIV/AIDS declined steadily from $63.8 \%$ among nonliterates to $30.9 \%$ among primary school educated respondents, $10 \%$ among secondary school educated respondents, and $0 \%$ among those with educational qualification of college and above. With regard to occupation, we observed that a significantly higher proportion of unemployed respondents/housewives (40.2\%) had not heard of HIV/AIDS $(P=0.002)$ while a significantly higher
TABLE 2: Distribution of participants depending on whether they have "heard of HIV/AIDS" or "not" $(n=200)$.

\begin{tabular}{|c|c|c|c|}
\hline $\begin{array}{l}\text { Sociodemographic } \\
\text { determinants }\end{array}$ & $\begin{array}{c}\text { Not heard about } \\
\text { HIV/AIDS } \\
(n=63)\end{array}$ & $\begin{array}{c}\text { Heard about } \\
\text { HIV/AIDS } \\
(n=137)\end{array}$ & $P$ value \\
\hline \multicolumn{4}{|l|}{ Age group (years) } \\
\hline $18-24$ years & $15(32.6 \%)$ & $31(67.4 \%)$ & \multirow{6}{*}{$0.027 ; \mathrm{S}$} \\
\hline $25-31$ years & $17(22.7 \%)$ & $58(77.3 \%)$ & \\
\hline $32-38$ years & $13(30.2 \%)$ & $30(69.8 \%)$ & \\
\hline $39-45$ years & $13(52 \%)$ & $12(48 \%)$ & \\
\hline $46-50$ years & $0(0 \%)$ & $3(100 \%)$ & \\
\hline$>50$ years & $5(62.5 \%)$ & $3(37.5 \%)$ & \\
\hline \multicolumn{4}{|l|}{ Gender } \\
\hline Male & $12(15 \%)$ & $68(85 \%)$ & \multirow{2}{*}{$<0.01 ;$ S } \\
\hline Female & $51(42.5 \%)$ & $69(57.5 \%)$ & \\
\hline \multicolumn{4}{|l|}{ Marital status } \\
\hline Single & $9(22.5 \%)$ & $31(77.5 \%)$ & \multirow{2}{*}{$0.238 ; \mathrm{NS}$} \\
\hline Married & $54(33.8 \%)$ & $106(66.2 \%)$ & \\
\hline \multicolumn{4}{|l|}{ Education } \\
\hline Nonliterate & $37(63.8 \%)$ & $21(36.2 \%)$ & \multirow{4}{*}{$<0.01 ; \mathrm{S}$} \\
\hline Primary & $21(30.9 \%)$ & $47(69.1 \%)$ & \\
\hline Secondary & $5(10 \%)$ & $45(90 \%)$ & \\
\hline $\begin{array}{l}\text { College and } \\
\text { above }\end{array}$ & $0(0 \%)$ & $24(100 \%)$ & \\
\hline \multicolumn{4}{|l|}{ Occupation } \\
\hline $\begin{array}{l}\text { Unemployed/ } \\
\text { housewives }\end{array}$ & $47(40.2 \%)$ & $70(59.8 \%)$ & $0.002 ; \mathrm{S}$ \\
\hline Daily wages & $8(32 \%)$ & $17(68 \%)$ & 0.862 ; NS \\
\hline Salaried & $5(12.8 \%)$ & $34(87.2 \%)$ & 0.009; S \\
\hline Business & $3(15.8 \%)$ & $16(84.2 \%)$ & $0.197 ; \mathrm{NS}$ \\
\hline \multicolumn{4}{|l|}{ Type of residence } \\
\hline Rural & $32(36.4 \%)$ & $56(63.6 \%)$ & \multirow{2}{*}{$0.246 ; \mathrm{NS}$} \\
\hline Urban & $31(27.7 \%)$ & $81(72.3 \%)$ & \\
\hline \multicolumn{4}{|l|}{ Type of family } \\
\hline Nuclear & $37(34.3 \%)$ & $71(65.7 \%)$ & \multirow{2}{*}{0.448 ; NS } \\
\hline Joint & $26(28.3 \%)$ & $66(71.7 \%)$ & \\
\hline
\end{tabular}

HIV: human immunodeficiency virus; AIDS: acquired immunodeficiency syndrome; S: significant; NS: nonsignificant.

proportion of participants belonging to salaried class $(87.2 \%)$ had heard about HIV/AIDS $(P=0.009)$ (Table 2$)$.

Among the 137 (68.5\%) respondents who had heard about HIV/AIDS, television was the main source of information for $130(94.9 \%)$, posters for $93(67.9 \%)$, and newspapers for $88(64.2 \%)$. A conversation or discussion with friends, health professionals, and teachers was a possible source of information about HIV/AIDS in 45 (32.8\%), 34 (24.8\%), and 26 (19\%) respondents, respectively. A conversation or discussion within family was the least reported source of information (8\%) (Table 3).

Of the 137 study participants who were further interviewed, 135 (98.5\%) could identify unprotected sex as the mode of HIV transmission. One hundred thirty-two (96.4\%) 
TABLE 3: Sources of information regarding HIV/AIDS ( $n=137)$.

\begin{tabular}{lcc}
\hline Source of information & Number & Percentage \\
\hline Television & 130 & $94.9 \%$ \\
Newspapers & 88 & $64.2 \%$ \\
Family & 11 & $8 \%$ \\
Friends & 45 & $32.8 \%$ \\
Teachers & 26 & $19 \%$ \\
Doctors & 34 & $24.8 \%$ \\
Posters & 93 & $67.9 \%$ \\
\hline
\end{tabular}

HIV: human immunodeficiency virus; AIDS: acquired immunodeficiency syndrome.

were aware of blood transfusion and use of unsterile needles and syringes as other modes of HIV transmission. Only $122(89.1 \%)$ knew about HIV transmission from infected mother to her child (Table 4). On correlating various sociodemographic variables with knowledge about each of the above mentioned principal modes of HIV transmission, we observed that awareness about unsafe sex as a possible mode was significantly higher among married participants $(P=$ 0.049). A statistically significant association was also noted between knowledge of unsterile needles and syringes as a transmission mode and education level (nonliterate versus primary versus secondary versus college and above; $P=$ $0.024)$ and urban residence $(P=0.01)$. Likewise a statistically significant difference was noted between the knowledge of married respondents about mother to baby transmission of HIV infection and their unmarried counterparts $(P=0.043)$ (Table 5).

On exploring the extent of misconceptions about HIV transmission, we observed that 45 (32.9\%) had a false perception that HIV can be transmitted by coughing/sneezing; $47(34.3 \%)$ thought that it can be transmitted by mosquito bite; 20 (14.6\%) thought that it can be transmitted by touching an HIV infected person; 26 (19\%) thought that it can be transmitted by working with an HIV infected person, while $32(23.3 \%)$ and 41 (29.9\%) incorrectly stated that it can be transmitted by eating with and by sharing towels/clothes/handkerchief of a person with HIV/AIDS, respectively (Table 4). On redefining the criteria of misconceptions as having "at least one misconception" we observed that $84(61.8 \%)$ of 136 respondents had misconceptions regarding HIV transmission (one respondent with "do not know" response to all the questions in this panel was excluded from the analysis). On further correlation with sociodemographic determinants, we noted that a statistically significant association existed between the presence of misconceptions and the education status of the respondents $(P<0.01)$ with a declining trend observed in the presence of misconceptions as the education level of the respondents increased $(81 \%$ in nonliterate participants, $78.3 \%$ in primary school educated participants, $46.7 \%$ in secondary school educated participants, and $41.7 \%$ in those educated till college and above).

Of the 137 participants who had heard about HIV/AIDS, only $68(49.6 \%)$ were aware of the availability of antiretroviral treatment (Table 4). Females seemed to be more aware regarding availability of antiretroviral treatment than males (63.8\% versus $35.3 \%$; $P=0.002$ ). Likewise married respondents seemed to more aware about this aspect than their unmarried counterparts (54.7\% versus $32.3 \%$; $P=0.045)$.

Use of condom as a preventive intervention was known to 136 (99.3\%) respondents. All (100\%) participants understood the role of loyalty to a single sexual partner and use of sterile disposable needles and syringes as precautionary measures to protect themselves from contracting HIV/AIDS. One hundred thirty-six (99.3\%) knew the importance of screening of blood before transfusion. No statistically significant correlation could be established between sociodemographic profile of the study participants and their awareness regarding HIV prevention strategies.

\section{Discussion}

In the present study, $68.5 \%$ of the participants had heard about HIV/AIDS. Similar findings were observed in a community based cross-sectional study conducted among rural youth of Saurashtra where nearly two-thirds of the respondents had ever heard about this infection [6]. Mass media (television, posters, and newspapers) followed by friends or peer group were the main sources of information for the respondents in our study. Our findings are in broad agreement with those of a study conducted by Subramaniam et al. that has reported mass media and friends as the chief sources of information on HIV/AIDS among rural south Indian women of Tamil Nadu [7]. Similar findings were reported in another study conducted in the underprivileged population of Chandigarh [8]. Television was also reported as the most important source of information about HIV/AIDS among medical and allied health science students of Bhubaneswar, Odisha [9]. Numerous other studies also highlight the pivotal role that mass media have played in creating HIV awareness among Indian population $[10,11]$. As with another study conducted in Raigad district, we also observed that discussion in family is a less common source of information about HIV and other sexual issues in Indian population [12]. Our findings show that the conservative atmosphere of the Indian society with its social restrictions and customs prevents free and open discussion about HIV/AIDS within family.

While majority of the respondents who had heard about HIV/AIDS had a good knowledge about HIV transmission modes, nearly $11 \%$ were still unaware of risk of HIV transmission from infected mother to her baby. Our findings are consistent with another study conducted among rural youth of Saurashtra, Gujarat, where the participants were less aware of mother to child transmission of HIV in comparison to other modes [6]. This lacuna in knowledge about HIV/AIDS among the Indian population needs to be addressed and stressed upon so as to encourage more and more women to undergo antenatal HIV testing and to ensure timely initiation of antiretroviral therapy in the pregnant women who are identified as HIV positive.

As with other studies conducted in Indian population, we observed that compared to males, a lower percentage of females have heard about HIV/AIDS. This finding highlights 
TABLE 4: Knowledge of participants regarding various aspects of HIV/AIDS.

\begin{tabular}{|c|c|c|c|}
\hline \multirow{2}{*}{ Question } & \multicolumn{3}{|c|}{ Response } \\
\hline & Yes & No & Do not know \\
\hline Have you ever heard about HIV/AIDS? $(n=200)$ & $137(68.5 \%)$ & $63(31.5 \%)$ & - \\
\hline \multicolumn{4}{|l|}{ Knowledge regarding modes of HIV transmission: $(n=137)$} \\
\hline (a) Unprotected sexual intercourse with HIV infected & $135(98.5 \%)$ & $2(1.5 \%)$ & - \\
\hline (b) Transfusion of infected blood & $132(96.4 \%)$ & $1(0.7 \%)$ & $4(2.9 \%)$ \\
\hline (c) Use of unsterile needles/syringes & $132(96.4 \%)$ & $2(1.4 \%)$ & $3(2.2 \%)$ \\
\hline (d) From an HIV infected mother to her baby & $122(89.1 \%)$ & $4(2.9 \%)$ & $11(8 \%)$ \\
\hline \multicolumn{4}{|l|}{ Myths and misconceptions regarding HIV transmission: $(n=137)$} \\
\hline \multicolumn{4}{|l|}{ Do you think HIV/AIDS can be transmitted by } \\
\hline (a) Coughing/sneezing? & $45(32.9 \%)$ & $75(54.7 \%)$ & $17(12.4 \%)$ \\
\hline (b) Mosquito bite? & $47(34.3 \%)$ & $73(53.3 \%)$ & $17(12.4 \%)$ \\
\hline (c) Touching a person with HIV/AIDS? & $20(14.6 \%)$ & $110(80.3 \%)$ & $7(5.1 \%)$ \\
\hline (d) Working with a person with HIV/AIDS? & $26(19 \%)$ & $107(78.1 \%)$ & $4(2.9 \%)$ \\
\hline (e) Taking food with a person with HIV/AIDS? & $32(23.3 \%)$ & $99(72.3 \%)$ & $6(4.4 \%)$ \\
\hline (f) Sharing towels/clothes/handkerchief of a person with HIV/AIDS? & $41(29.9 \%)$ & $82(59.9 \%)$ & $14(10.2 \%)$ \\
\hline Knowledge regarding availability of antiretroviral treatment $(n=137)$ & $68(49.6 \%)$ & $19(13.9 \%)$ & $50(36.5 \%)$ \\
\hline \multicolumn{4}{|l|}{ Knowledge regarding preventive interventions for HIV/AIDS: $(n=137)$} \\
\hline (a) Use of condom during sexual intercourse & $136(99.3 \%)$ & - & $1(0.7 \%)$ \\
\hline (b) Loyalty to a single partner & $137(100 \%)$ & - & - \\
\hline (c) Use of sterile disposable needles and syringes & $137(100 \%)$ & - & - \\
\hline (d) Transfusion of screened and tested blood units & $136(99.3 \%)$ & $1(0.7 \%)$ & - \\
\hline
\end{tabular}

HIV: human immunodeficiency virus; AIDS: acquired immunodeficiency syndrome.

that members of the biologically more susceptible gender are largely unaware of the disease to which they are highly vulnerable, a phenomenon driven by the male dominated Indian society that denies the females education and access to information [13].

Education was found to have a direct relation to the awareness levels of the respondents. Not only were the nonliterate subjects less likely to have heard about HIV/AIDS, but also the awareness of some aspects of HIV transmission such as spread by sharing of needles and syringes was significantly lower in the nonliterate subjects. A study conducted in rural district of Raigad also found the level of awareness to be significantly lower in illiterates as compared to literates [12]. Malleshappa et al. have also reported literates to have better knowledge of HIV/AIDS than nonliterates [14]. Education not only increases the accessibility to information but also enables better understanding and interpretation of the informative material and eventually its reflection in one's personal risk reduction strategies.

With regard to occupation, we observed that a significantly lower number of unemployed men and housewives had heard of HIV/AIDS while the proportion of respondents from the salaried class who had heard about it was significantly higher. Differences in knowledge between different occupational groups have also been highlighted in another study conducted in Hyderabad where students and people in service and business were found to have high awareness levels while lowest awareness levels were seen in housewives, cultivators, agriculture labourers, and industrial workers [15].
While we could not establish a correlation between age of respondents and HIV awareness, lower awareness levels among younger populations have been reported in other studies [12].

Married respondents seemed to be more aware of certain aspects of HIV transmission such as unsafe sex and mother to child HIV transmission as well as antiretroviral treatment. Higher awareness levels in married as compared to unmarried respondents have also been documented in other studies [12].

While the knowledge of HIV transmission modes and preventive strategies was good among the respondents who were interviewed, the prevalence of misconceptions regarding HIV transmission was high. Our findings are consistent with other studies where casual contact, mosquito bite, bed bugs, public toilets, pools, and sharing meals have been considered as modes of HIV transmission by the participants $[6,14,16-18]$. As with other studies misconceptions were more among the respondents who were nonliterate $[14,19$, 20]. A summary of some of the previous similar studies undertaken in different demographic regions of the Indian subcontinent is given in Table 6 .

\section{Conclusion}

Our study highlights that a significant proportion of Indian population is unaware of HIV/AIDS to the extent that they have not even heard of it. There is a strong need to raise the levels of HIV awareness among the population 


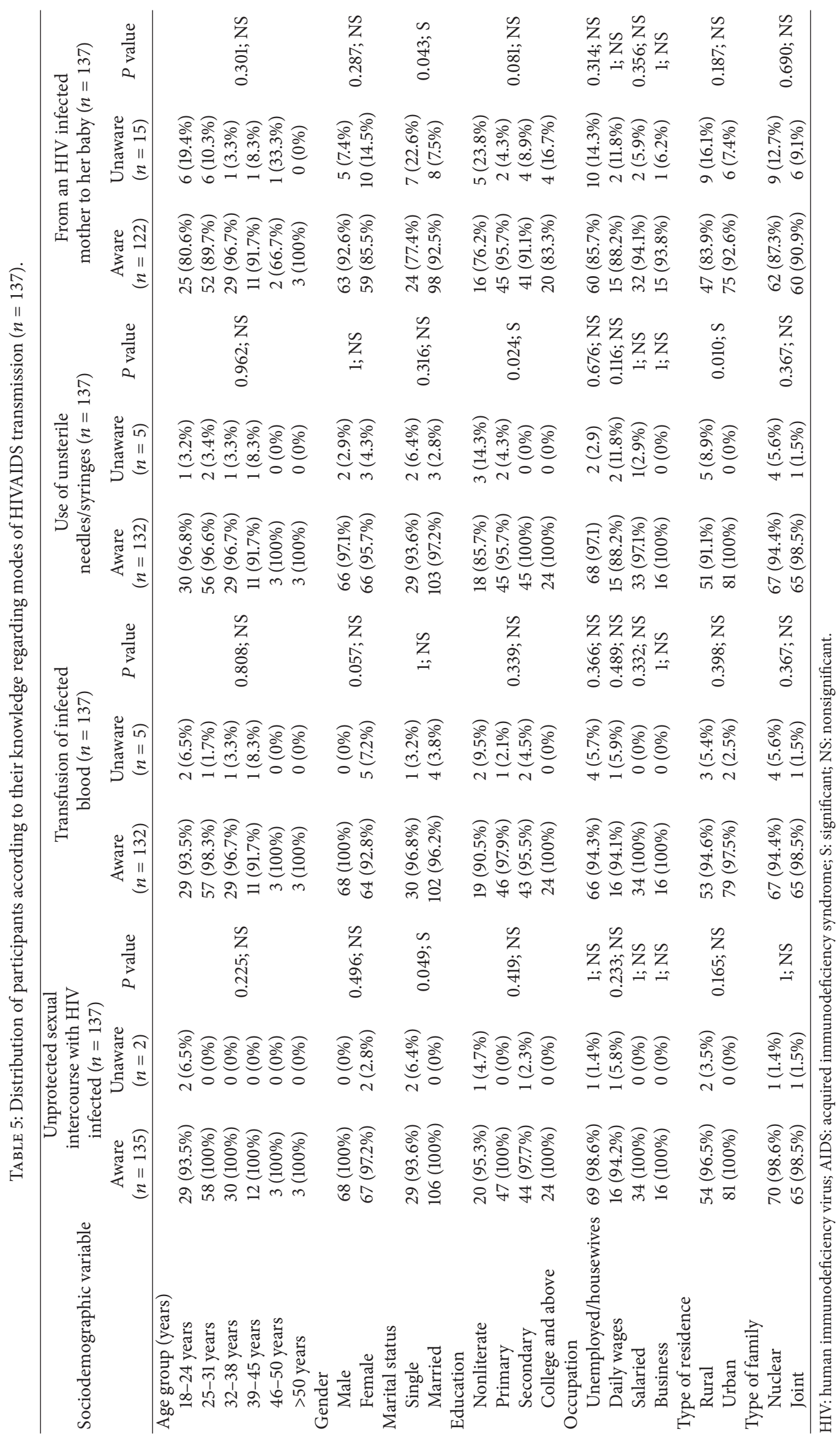




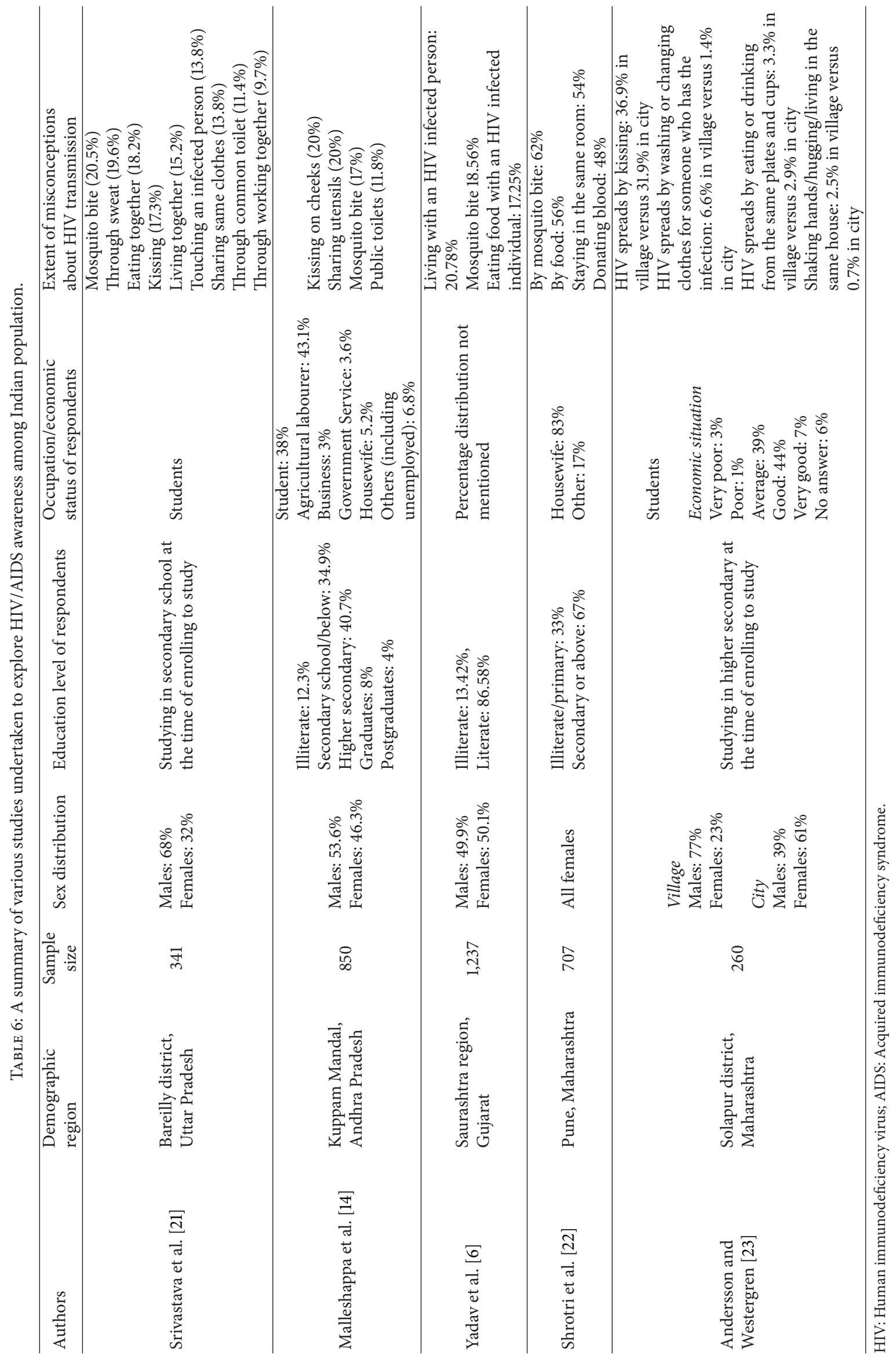


especially among women and nonliterate members of the community. The prevalence of misconceptions regarding HIV transmission is also high in the Indian population. While media has played a crucial role in attaining the present level of knowledge about HIV/AIDS in the community, much efforts are still needed in this direction including education in conjunction with evolution of novel creative strategies to reach out to more and more people, make them aware about HIV/AIDS, improve their existing knowledge about this disease, and demystify their myths and misconceptions.

\section{Conflict of Interests}

The authors declare that there is no conflict of interests regarding the publication of this paper

\section{References}

[1] "UNAIDS Report on the global AIDS epidemic," 2013, http:// www. unaids.org/en/media/unaids/contentassets/documents/ epidemiology/2013/gr2013/UNAIDS_Global_Report_2013_en .pdf.

[2] UNAIDS, "AIDS epidemic update," 2009, http://www.unaids. org/en/KnowledgeCentre/HIVData/EpiUpdate/EpiUpdArchive /2009/default.asp.

[3] "Annual Report 2010-11. Department of AIDS Control. National AIDS Control Organization. Ministry of Health \& Family Welfare. Government of India," http://www.nacoonline .org/upload/REPORTS/NACO\%20Annual\%20Report\%202010 -11.pdf.

[4] S. Hawkes and K. G. Santhya, "Diverse realities: sexually transmitted infections and HIV in India," Sexually Transmitted Infections, vol. 78, supplement 1, pp. i31-i39, 2002.

[5] UNAIDS, "National response brief-India," 2004, http://www. unaids.org/nationalresponse/result.asp.

[6] S. B. Yadav, N. R. Makwana, B. N. Vadera, K. M. Dhaduk, and K. M. Gandha, "Awareness of HIV/AIDS among rural youth in India: a community based cross-sectional study," Journal of Infection in Developing Countries, vol. 5, no. 10, pp. 711-716, 2011.

[7] T. Subramanian, M. D. Gupte, and R. Ezhil, "AIDS: an understanding in rural women of South-India," Indian Journal of Sexually Transmitted Diseases, vol. 28, no. 1, pp. 10-14, 2007.

[8] V. Bhatia, H. M. Swami, and A. P. Kaur, "An intervention study to enhance AIDS awareness among underprivileged population in Chandigarh," Indian Journal of Dermatology, Venereology and Leprology, vol. 70, no. 2, pp. 87-91, 2004.

[9] A. Chauhan, M. Hussain, S. Pati, S. Nallala, and J. Mishra, "Knowledge and attitudes related to HIV/AIDS among medical and allied health science students," Indian Journal of Community Health (IJCH), vol. 23, no. 2, 2012.

[10] S. S. Tibdewel and S. K. Wadhva, "HIV/AIDS awareness among hospital employees," Indian Journal of Medical Sciences, vol. 55, no. 2, pp. 69-72, 2001.

[11] N. Chatterjee, "AIDS-related information exposure in the mass media and discussion within social networks among married women in Bombay, India," AIDS Care-Psychological and SocioMedical Aspects of AIDS/HIV, vol. 11, no. 4, pp. 443-446, 1999.

[12] S. Solat, G. D. Velhal, H. Mahajan, A. Rao, and B. Sharma, "Assessment of awareness about HIV/AIDS and operationalization of interventions in rural population of Raigad district,
India," International Journal of Scientific and Research Publications, vol. 2, no. 11, 2012.

[13] United Nations Development Programme, "Gender: impact of HIV and AIDS in India," 2006, http://www.undp.org/content/ dam/india/docs/gender.pdf.

[14] K. Malleshappa, S. Krishna, and Shashikumar, "Awareness and attitude of youth toward HIV/AIDS in rural Southern India," Biomedical Research, vol. 23, no. 2, pp. 241-246, 2012.

[15] R. T. Sudha, D. T. Vijay, and V. Lakshmi, "Awareness, attitudes, and beliefs of the general public towards HIV/AIDS in Hyderabad, a capital city from South India," Indian Journal of Medical Sciences, vol. 59, no. 7, pp. 307-316, 2005.

[16] Q. Sikander, R. Malik, and R. Afzal, "Knowledge, attitude and practices of college students of Rawalpindi regarding HIV/AIDS," Pakistan Journal of Medical Research, vol. 39, pp. 29-34, 2000.

[17] S. K. Ganguli, P. P. Rekha, N. Gupte, and U. A. Charan, "AIDS awareness among undergraduate students, Maharashtra," Indian Journal of Public Health, vol. 46, no. 1, pp. 8-12, 2002.

[18] A. D. Meundi, A. Amma, A. Rao, S. Shetty, and A. K. Shetty, "Cross-sectional population-based study of knowledge, attitudes, and practices regarding HIV/AIDS in Dakshina Kannada district of Karnataka, India," Journal of the International Association of Physicians in AIDS Care, vol. 7, no. 1, pp. 27-34, 2008.

[19] B. K. Ambati, J. Ambati, and A. M. Rao, "Dynamics of knowledge and attitudes about AIDS among the educated in southern India," AIDS Care, vol. 9, no. 3, pp. 319-330, 1997.

[20] G. Bhattacharya, C. Cleland, and S. Holland, "Knowledge about HIV/AIDS, the perceived risks of infection and sources of information of Asian-Indian adolescents born in the USA," AIDS Care-Psychological and Socio-Medical Aspects of AIDS/HIV, vol. 12, no. 2, pp. 203-209, 2000.

[21] A. Srivastava, S. E. Mahmood, P. Mishra, V. P. Shrotriya, and I. Shaifali, "Adolescence awareness; a better tool to combat HIV/AIDS," National Journal of Community Medicine, vol. 2, no. 1, pp. 86-90, 2011.

[22] A. Shrotri, A. V. Shankar, S. Sutar et al., "Awareness of HIV/AIDS and household environment of pregnant women in Pune, India," International Journal of STD and AIDS, vol. 14, no. 12, pp. 835-839, 2003.

[23] C. Andersson and C. Westergren, Still Scant and Insufficient Knowledge about HIV/AIDS among Teenagers in Solapur District, Maharashtra State, India, The Sahlgrenska Academy at University of Gothenburg, Gothenburg, Sweden, 2004, http://www.vgregion.se/upload/SkaS/FoU/HIVIndia.pdf. 


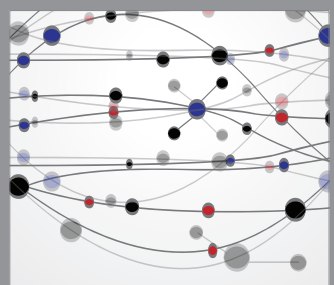

The Scientific World Journal
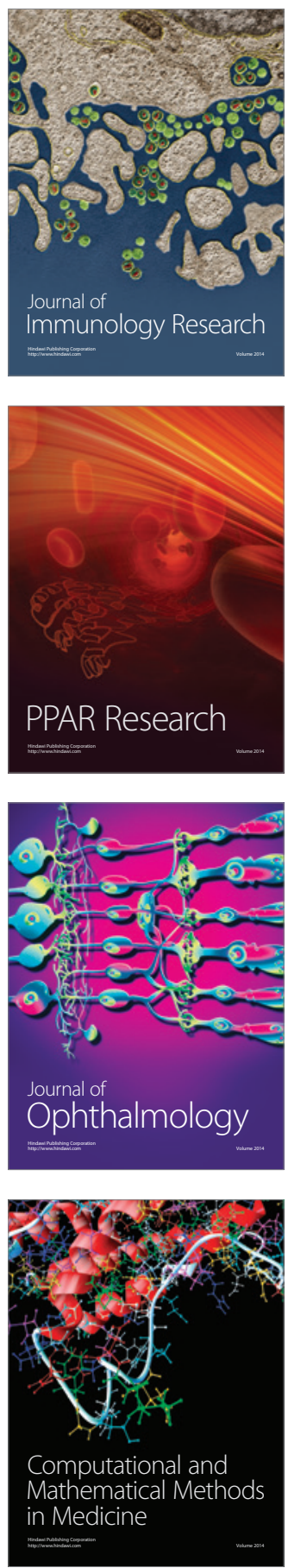

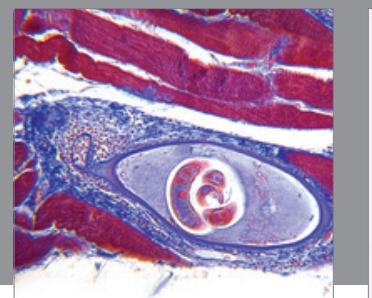

Gastroenterology

Research and Practice
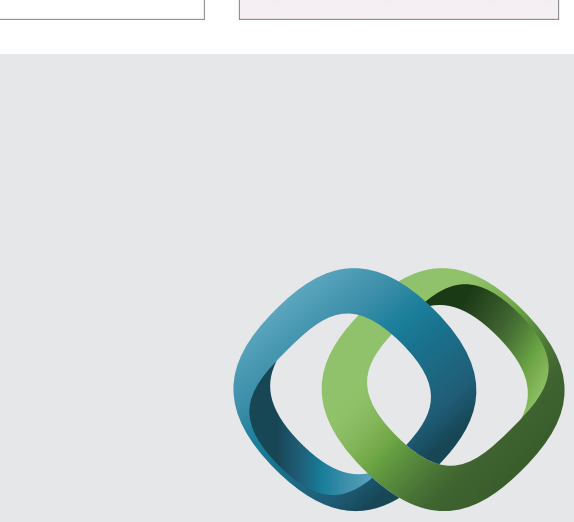

\section{Hindawi}

Submit your manuscripts at

http://www.hindawi.com
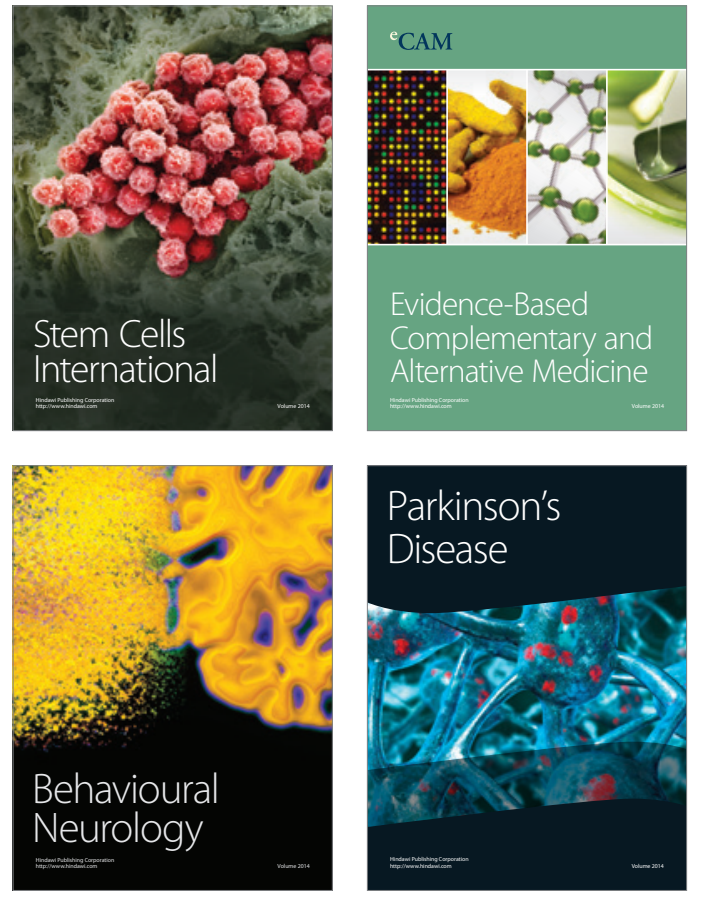
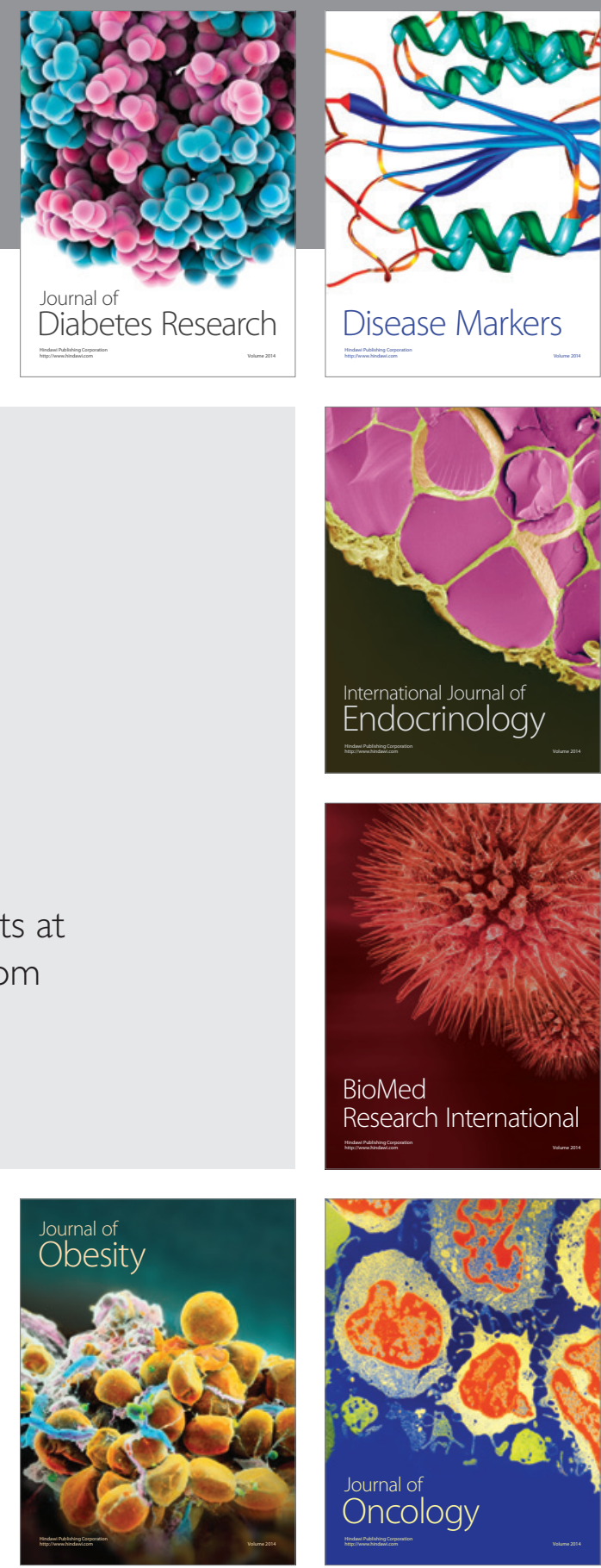

Disease Markers
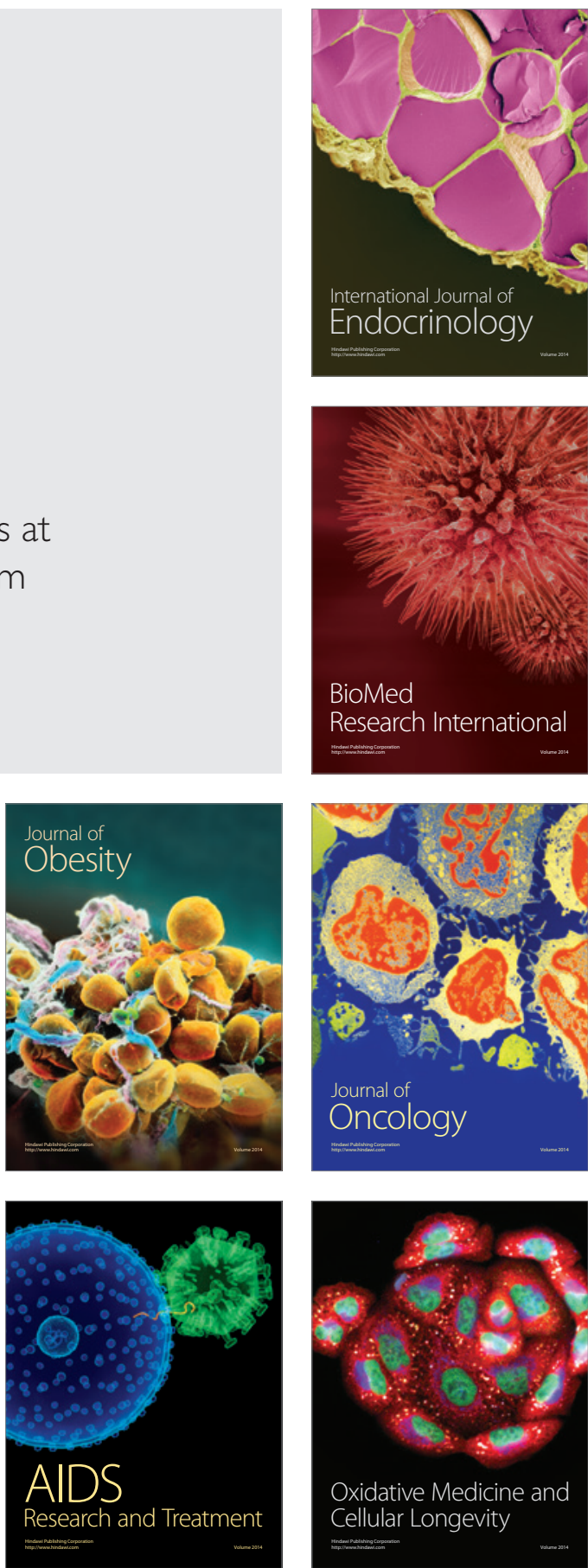